\title{
Okul öncesi dönem çocuklarının ego sağlamlık düzeylerinin incelenmesi
}

\section{The investigation of the level of ego resilience of preschool children}

Makale Geçmişi

Geliş : :07 Şubat 2018

Düzeltme : 02 Mart 2018

Kabul : 13 Mart 2018

Çevrimiçi : 13 Mart 2018

\section{Makale Türü}

Özgün Makale

\author{
Asude Balaban Dağal ${ }^{1}$, Dilan Bayındır ${ }^{2}$
}

\begin{abstract}
Öz: Ego sağlamlığı risk faktörlerine rağmen olumlu gelişme eğilimi olarak tanımlanmaktadır. Çocuğun gelişimi açısından risk oluşturan faktörler ve bu risk faktörlerine rağmen gelişimini olumlu devam ettirebilmesine olanak veren koruyucu faktörler bireysel, ailesel ve çevresel boyutta ele alınmaktadır (Brown, Barbarin ve Scott, 2013; Gizir 2007). Okul öncesi dönem çocuklarla ego sağlamlık düzeyini etkileyen değişkenleri inceleyen Türkiye'deki araştırma sayısı oldukça sınırlıdır. $\mathrm{Bu}$ nedenle araştırmanın amacı, 50-72 aylık, okul öncesi eğitim kurumlarına devam etmekte olan çocukların ego sağlamlık düzeylerinin yaşlarına, cinsiyetlerine, anne-baba yaşlarına, anne-baba eğitim düzeyine, sahip oldukları kardeş sayılarına ve evde bakıcı olup olmamasına göre farklılaşıp farklılaşmadığını tespit etmek olarak belirlenmiştir. Araştırma betimsel tarama modelinde tasarlanmıştır. Veriler 2015-2016 eğitim-öğretim yılında, okul öncesi eğitim kurumlarına devam eden çocukların annelerinden toplanmıştır. Araştırmada yaş ortalaması 65.03 ay olan 775 çocuğa ulaşılmıştır. Araştırmaya katılan çocukların 397'si kız 378'i ise erkektir. Araştırmada veri toplama aracı olarak Eisenberg ve arkadaşları tarafindan 1996 yılında geliştirilen ve Önder ve GülayOgelman (2011) tarafından Türkçe'ye uyarlanan Ego Sağlamlığı Ölçeği (Anne Formu) kullanılmıştır. Araştırma sonuçlarına göre çocukların ego sağlamlık düzeyleri cinsiyet açısından değerlendirildiğinde kızlar lehine anlamlı bir fark elde edilmiştir. Diğer değişkenlerin ego sağlamlık düzeyi üzerindeki etkisi ise istatistiksel olarak anlamlı bulunmamıştır.
\end{abstract}

Anahtar Kelimeler: Okul öncesi dönem, ego sağlamlığı, 50-72 aylık çocuklar

Abstract: Ego resiliency is defined as positive development tendency despite risk factors. Factors that constitute a risk for the development of the child and protective factors that enable the development to continue in spite of these risk factors are considered at the individual, familiar and environmental dimensions (Brown, Barbarine and Scott, 2013; Gizir, 2007). Since the number of studies examining the variables affecting ego resiliency with preschool children is limited in the relevant Turkish literature, the aim of this research is to determine the ego resiliency levels of the 50-72 months old children who are attending in preschool according to age, gender they attend, , ages of their parents, education level of the parents, the number of brothers/sisters they have and presence of a care giver. The research was designed in a descriptive survey model. The data were collected from children's mothers who were attending preschool education institutions in the academic year of 2015-2016. 775 children with a mean age of 65.03 were reached in the survey. 397 girls and 378 girls are participating in the research. The Ego Resiliency Scale (Mother Form) that was developed by Eisenberg and her collegues in 1996 and adapted into Turkish by Önder and Ogelman (2011) was used as data collection tool in the study. According to the results of the research, when the ego resiliency levels were evaluated in terms of gender, it was found meaningful in favor of the girls. However, the ego resiliency of children does not differ statistically according to other variables.

Keywords: Preschool period, ego resiliency, 50-72 month old children

\footnotetext{
* Bu araştırma, 19-21 Ekim 2017 tarihleri arasında İstanbul'da düzenlenen III. Uluslararası Afro - Avrasya Araştırmaları Kongresi'nde sözlü bildiri olarak sunulmuştur.

${ }^{1}$ Marmara Üniversitesi, Atatürk Eğitim Fakültesi, Temel Eğitim Bölümü, asudebd@marmara.edu.tr

${ }^{2}$ Balıkesir Üniversitesi, Necatibey Eğitim Fakültesi, Temel Eğitim Bölümü, dilan.bayindir@balıkesir.edu.tr
} 


\section{SUMMARY}

\section{Introduction}

Ego resiliency is defined as positive development tendency despite risk factors. Factors that constitute a risk for the development of the child and protective factors that enable the development to continue in spite of these risk factors are considered at the individual, familial and environmental dimensions (eg. Brown, Barbarine and Scott, 2013; Gizir, 2007). For example, premature birth (Bradley et all., 1994), low birth weight (Rak and Patterson, 1996), chronic illnesses (Hechtman, 1991 cited in Zolkoski and Bullock, 2012; McCubbin, Balling, Possin, Frierdich and Bryne, 2002) are the most significant individual risk factors. On the other hand, easy temperament (Wyman, Cowen, Work and Parker, 1991), developed control skills (Taylor, Eisenberg, Spinrad and Widaman, 2013) and cognitive skills (Coyne and Thompson, 2011; Keenan and Shaw, 1997) are protective individual factors. Although negative parenting attitudes (Balaban-Dağal, Önder and Bayındır, 2016; Power, 2004) are important risk factors in familial dimension, some other factors, such as close partner relationships, supportive parent-child interactions, social support, stable and adequate income are among the familiar protective factors (Benzies and Mychasiuk, 2009). In environmental level, negative life experiences such as abuse, violence, neglect, minority and racial discrimination are predictors of negative life outcomes (Brooks, 2006; Luther, 1991; Masten, 2011, Rak and Patterson, 1996). The use of early prevention and intervention programs, safe neighborhood settings, provision of support services, access to adequate health services, economic benefits for families, religious and spiritual organizations could be considered as protective environmental factors (Alvord and Grados, 2005, Benzies and Mychasiuk, 2009). According to Ungar et al. (2007), the individual ego resiliency capacity is the result of interactions between these personal and environmental factors.

Since the number of studies examining the variables affecting ego resiliency with preschool children is limited in the relevant Turkish scientific literature, the aim of this research is to determine the ego resiliency levels of the 50-72 months old children who are attending preschools according to age, gender, type of school they attend, ages of their parents, education level of the parents, the number of brothers/sisters they have and who they were raised by.

\section{Method}

The research was designed in a descriptive survey model. The data were collected from the mothers of children, who were attending preschool education institutions in the academic year of 2015-2016. 775 children, with a mean age of 65.03 months were reached by the survey. 397 girls and 378 girls participated in the research. The Ego Resiliency Scale (Mother Form) was used as the data collection tool in the study. The scale was developed in 1996 by Eisenberg and her colleagues and it was adapted 
to Turkish by Önder and Gülay-Ogelman (2011). The scale, consisting of 12 items, is a 9 point likert type measure. The cronbach alpha value of the mother form is .86 (Önder and Gülay-Ogelman, 2011).

In the beginning of the study, permission to use the scale was taken from the research developers and the İstanbul Directorate of Ministery of Education approved the collection of data from schools. The scale was distributed to the mothers through the teachers and the data were collected back by the same way. ANOVA and independent group $t$ test were used in the analysis of the data. In addition, whenever the results of the Levene test indicated that the variances were not equal, then Welch test was applied.

\section{Results}

The difference in ego resiliency was found to be meaningful in favor of female children $(t(756.647)=2.076 ; p=.038)$. According to this, it can be said that children's ego resiliency differ according to their gender. No significant difference were found in ego resiliency at age group (5057months, 58-64 months, 65-72 months), mother's age (30and under 30, 31-40, 41 and more), father's age (30and under 30, 31-40, 41 and more), mother's education level (primary school, high school, college), father's education level (primary school, high school, college), number of brothers/sisters or presence of a care giver at home $\left(\mathrm{F}_{\text {(agegroup) }}=.445 ; \mathrm{p}=.641, \mathrm{WelchF}_{\text {(mother'sageage) }}=.478 ; \mathrm{p}=.620\right.$; $\left.\mathrm{WelchF}_{\text {(fatyher'sageage) }}=.478 ; \mathrm{p}=.620, \mathrm{~F}_{\text {(mother's education level) }}=2182 ; \mathrm{p}=.114\right) ; \mathrm{WelchF}_{\text {(father's education level) }}=1.477$; $\left.\mathrm{p}=.230 ; \mathrm{WelchF}_{\text {(number of brother/sister) }}=1.905 ; \mathrm{p}=.150 ; \mathrm{t}_{(\text {having a carer) }}(764)=324 ; \mathrm{p}=.746\right)$.

\section{Conclusion and Discussion}

At the end of the study, it was found that children ego resiliency level scored higher in favor of the female children. From this result, it can be said that girls are more resilient than the boys at age 50 to 72 months. This result of the study can be overlapped with the findings of another research that found that before the adulthood boys have more risk, after the adulthood girls have more risk about the ego resiliency (Gamble ve Zigler, 1986; Rutter, 1989). But differentiating from this research Taylor and his friends' research and also Önder and his friends results indicate that ego resiliency do not differ according to sex (Taylor et al. 2013).

In this study, the family's education level didn't make any difference in ego resiliency but there are some researches that show that the family's education level makes differences in ego resiliency but these researches were for the adolescents (Gianesini, 2011; Sangma, 2014; Sue-Lynn ve Yoo'nun, 2015). At this point, the differentiation can be attributed to the difference of age groups.

As in this research, Sangma's (2014) research present that the number of the family members doesn't make any differences in ego resiliency levels of children. But another research indicates that number of the family members at age 16 to 30 makes differences in ego resiliency (Gianesin, 2011). 
There are some limitations that need to be mentioned about the research. The most important limitation of the study is that both the demographic data and the data of the ego resiliency of the children are evaluated by the information received from their mothers. Collection of data from different sample groups, and reconducting the research by reaching different socio-economic levels will be important for the identification of children at risk in terms of ego resiliency. 


\section{GíRiş}

Ego sağlamlığı en basit anlamıyla, risk faktörlerine rağmen olumlu gelişme eğilimi olarak tanımlanabilir. Türkçe alan yazında bu kavram, ego sağlamlığı (Önder ve Ogelman-Gülay, 2011), yılmazlık (Çelik, 2013) veya psikolojik sağlamlık (Gizir, 2007) gibi farklı terimlerle adlandırılmaktadır. Çocukların ve ergenlerin ego sağlamlıklarının yüksek olarak sınıflandırılabilmesi için öncelikle bireyi tehdit eden risk faktörleri bulunmalı ve ikinci olarak bu risk faktörlerine rağmen bireyin adaptasyon ve gelişme kapasitesi yüksek olmalıdır (Masten ve Coatsworth, 1998). Yüksek ego sağlamlığına sahip bireyler değişen koşullara uyum sağlayabilir, davranışlarını gerektiği gibi düzenleyebilir ve problem çözme stratejilerini esnek bir şekilde kullanabilir. Ungar ve arkadaşlarına (2007) göre, ego sağlamlığının güncel tanımı ekolojik sistem yaklaşımının bakış açısı ile ele alınmaktadır Bu tanıma göre ise, bireyin sahip olduğu ego sağlamlık kapasitesi kişisel ve çevresel faktörler arasındaki etkileşimlerin sonucu olarak ortaya çıkmakta ve bu tanım sonuca katkı sağlayan süreçleri de içermektedir.

Ego sağlamlık düzeyleri yüksek çocuk ve ergenlerde sosyal yetkinlik (Block ve Block, 2006), problem çözme becerileri, iyimserlik, amaç ve gelecek duygusu (Stipek, Recchia ve McClintic, 1992) güçlüdür. Prince-Embury'e (2015) göre ego sağlamlığg, akademik başarı, okula devam süresi ve okul mezun olabilmeyi destekleyen bir unsurdur. Benzer şekilde Kwok, Hughes ve Luo (2007) 445 çocuğu, birinci sınıf ve bir yıl sonrasında değerlendirerek ego sağlamlığının eş zamanlı ve gelecekteki başarı için yordayıcı bir faktör olduğunu belirtmişlerdir. Bunlara paralel olarak Bayındır, Önder ve Balaban-Dağal (2016) Türkiye'deki okul öncesi dönem çocuklarla yaptıkları bir araştırmanın sonunda ego sağlamlığının okula hazır bulunuşluk ile ilişkili olduğunu göstermiştir.

Çocukların ego sağlamlık düzeyleri ile ilgili koruyucu ve risk faktörleri bireysel, çevresel ve bağlamsal boyutta ele alınmaktadır (örn. Brown, Barbarin ve Scott, 2013; Gizir, 2007). Bu boyutlar altında yer alan faktörler aşağıdaki bölümlerde açıklanmaktadır.

\section{Bireysel Boyutta Risk Faktörleri ve Koruyucu Faktörler}

Bireysel olarak tanımlanan risk faktörlerinden biri erken doğumdur (Bradley vd., 1994). Hamileliğin 37. haftasından önce doğan çocuklar premature çocuklar olarak değerlendirilir ve bu çocuklar erken doğumundan kaynaklı pek çok riske maruz kalırken, aynı zamanda bu unsur ebeveynler için de bir stres durumu oluşturmaktadır. Doğumsal kusurlar ve düşük doğum ağırlığı da biyolojik olarak birincil sıradaki risk faktörleri arasındadır (Rak ve Patterson, 1996). Her iki durumun görülme sebepleri başında düşük gelirli annelerin uygun beslenme ve tıbbi 
bakımdan yoksun olmaları ile annelerin uyuşturucu madde kullanımları yer almaktadır. Bunun dışında kanser, dikkat eksikliği hiperaktivite bozukluğu gibi kronik hastalıklar bireysel boyutta en önemli risk faktörleri arasında yer alır (Hechtman, 1991 akt. Zolkoski ve Bullock, 2012; McCubbin, Balling, Possin, Frierdich ve Bryne, 2002).

Koruyucu faktörlerin başında ise mizaç özellikleri vardır. Kolay mizaç, ego sağlamlığı ile ilgilidir (Wyman, Cowen, Work and Parker, 1991). Mizaca bağlı öz düzenleme becerileri birincil bireysel koruyucu faktörler arasındayken (Alvord ve Grados, 2005; Benzies ve Mychasiuk, 2009), çocukların kontrol becerilerinin ego sağlamlığını pozitif olarak yordadığını görgül araştırma sonuçları da göstermektedir (Taylor, Eisenberg, Spinrad ve Widaman, 2013). Kontrollerini istendik şekilde sağlayabilen bireyler, stresli durumlara uyum sağlamakta avantaja sahiptir (Eisenberg vd, 2004). Bunun yanı sıra duyguları düzenleme becerileri de ego sağlamlığı üzerinde yordayıcı nitelik taşır. Rydell, Berlin ve Bohlin (2003) yaptıkları boylamsal çalışmada duygu düzenleme becerilerinin düşüklüğünün dışsallaştırma problemleri ile düşük prososyal davranışların yordayıcısı olduğunu göstermiştir. Benzer şekilde diğer çalışmalar da ego sağlamlığının sosyal yetkinlik ile ilişkili olduğunu vurgulamaktadır (Coyne ve Thompson, 2011; Keenan ve Shaw, 1997).

Bireysel seviyede, ego sağlamlığı bilişsel beceriler ile de ilgilidir (Coyne ve Thompson, 2011; Keenan ve Shaw, 1997). Üst düzey zihinsel beceriler çocukların alternatif baş etme stratejileri düşünmelerini mümkün kılabilir (Compas, Jaser ve Benson, 2009). Üst bilişsel becerilerden dikkatin düzenlenmesi becerisinin, negatif duygularla baş etmeyi kolaylaştırdığı ve bu sayede psikolojik sağlamlık üzerinde olumlu etkileri olduğunu söyleyen görüşler vardır (Derryberry ve Reed, 1996; Lengua, Sandler, West, Wolchik ve Curran, 1999; Rothbart, Ahadi ve Evans, 2000).

\section{Ailesel Boyutta Risk Faktörleri ve Koruyucu Faktörler}

Bir araştırmada negatif ebeveynliğin dikkat ve davranışı düzenleme becerilerini olumsuz etkileyerek dolaylı olarak ego sağlamlığını olumsuz etkilediğini bulgulanmıştır (Taylor, Eisenberg, Spinrad ve Widaman, 2013). Baskıcı duyarsız veya kontrolcü ebeveynler çocukların bağımsız baş etme becerileri ve bağımsız davranışlarının gelişimini olumsuz etkilerken, duyarlı ebeveynler ise etkili baş etme becerileri konusunda model olabilir (Power, 2004). Türkiye'de okul öncesi yaş grubu ile yapılan bir araştırmada, otoriter ebeveynlik stili gösteren ebeveynlerin çocuklarının daha düşük oranlarda ego sağlamlığı gösterdiği bulgulanmıştır (Önder, BalabanDağal ve Bayındır, 2016). McLoyd ve Wilson'ın (1990) araştırmasının sonuçları, annenin stresinden kaynaklanan olumsuz ebeveyn davranışlarının çocuklardaki psikolojik sıkıntı ile 
ilişkili olduğunu göstermektedir. Annenin stresi çocukların içselleştirme davranış problemlerinde önemli rol oynamaktadır (Keenan ve Shaw, 1997). Mathiesen, Sanson, Stoolmiller ve Karevold (2009) 18 aydan, 4,5 yaşa kadar izledikleri çocuklarda içselleştirme problemlerinin en önemli yordayıcısının annenin depresif belirtileri ve aile stres düzeyi olduğunu göstermişlerdir.

Hechtman (1991 akt. Zolkoski ve Bullock, 2012), dikkat eksikliği ve hiperaktivite bozukluğu teşhisini çocukken alan yetişkinlerle yaptığı bir araştırmada, onlara inanan bir ebeveyn ya da öğretmen gibi bir yetişkinin bu çocukların hayatlarında çok olumlu etkileri olduğunu göstermiştir. Annenin olumlu ve iyimser ruh hali çocuklarda olumlu duygu düzenleme becerilerini teşvik ederken, olumsuz olaylarla başa çıkmakta yardımcı olmaktadır (Keenan ve Shaw, 1997). Bradley ve diğerleri (1994) yoksulluk içinde yaşayan 243 prematüre doğan düşük kilolu çocukların içinde sadece 26'sının 3 yaşında normal zihinsel, sosyal ve sağlık gelişim parametreleri gösterdiğini ortaya koymuştur. Ego sağlamlığı gösteren çocukların erken dönemlerde diğer çocuklara göre en belirgin farkı daha kabul edici ve uyarıcıların bolca sağlandığı bir bakıma sahip olmalarıdır. Benzer şekilde Türkiye'de yapılan bir araştırma, özellikle düşük gelir düzeyli ailelerde annenin sıcaklık ve ilgisinin çocuğun gelişimini olumlu şekilde etkilediğini göstermiştir (Baydar ve Akçınar, 2015). Dezavantajlı ortamlarda katı ebeveyn yönergeleri, ebeveyn sıcaklığı içeriyorsa, yoksul çocukları çevresel tehditlere karşı da korumaktadir (McLoyd, 1998).

Yakın eş ilişkileri, destekleyici ebeveyn-çocuk etkileşimleri, sosyal destek ve istikrarlı ve yeterli bir gelir gibi diğer bazı unsurlar ailesel koruyucu faktörler arasındadır (Benzies ve Mychasiuk, 2009).

\section{Çevresel Boyutta Risk Faktörleri ve Koruyucu Faktörler}

Ego sağlamlığının oluşumu için hem okulların niteliği gibi ortamsal şartların, hem de içinde yaşanılan kültürün önemi vurgulanmaktadır (Wolkow ve Ferguson, 2001). Kötü muamele, şiddet, istismar, ihmal, azınlık ve ırk ayrımcılıklarına maruz kalmak gibi negatif yaşam deneyimleri olumsuz yaşam çıktılarının yordayıcılarıdır (Brooks, 2006; Luthar, 1991; Masten, 2011; Rak ve Patterson,1996).

Erken önleme ve müdahale programlarının yürütülmesi, güvenli mahalle ortamları, destek hizmetlerinin sağlanması, yeterli sağlık hizmetlerine erişilebilirlik, aileler için ekonomik yardımlar ve dini ve manevi organizasyonlar ise öne çıkan çevresel koruyucu faktörler arasındadır (Alvord ve Grados, 2005; Benzies ve Mychasiuk, 2009). 
Okulda ve ev dışında destek görmeyen çocuklar, etkili baş etme stratejileri, sosyal yetkinlik ve duygusal iyi olma hali geliştirmede önemli kaynaklardan yoksun durumdadır (Compas vd., 2009). Ebeveynlerin dişında ilgili, destek sağlayan bir yetişkin risk altındaki çocuklar ve ergenler için koruyucu bir faktördür (Gilligan, 2000; Smokowski, Reynolds ve Bezruczko, 2000). Özellikle ebeveynlerin eğitim seviyeleri düştükçe bu faktör önem kazanmaktadır. Örneğin, sevilen öğretmenler çocukların hayatlarında en çok belirtilen pozitif rol modelleri arasındadır. Bu öğretmenler sadece akademik yetkinliği kolaylaştıran eğitmenler değildir, aynı zamanda kişilik gelişimi için önemli destek sağlamaktadır (Werner, 1990 akt.Smokowski vd., 1999). Yakın çevredeki komşular da çocukların olumlu gelişimlerine katkı sağlar. Düşük eğitimli annelerin çocuklarının prososyal davranışlarının, komşulardan gelen destek ile arttığ bulunmuştur (Baydar ve Akçınar, 2015). Bunun yanı sıra, çocuk ya da ergenlerin akranları tarafindan kabulü çevresel koruyucu faktörler arasındadır (Criss, Pettit, Bates, Dodge ve Lapp, 2002). Örneğin Felsman (1989 akt. Ungar vd., 2007) Kolombiya'da 16 yaşın altındaki 300 sokak çocuğuyla yaptığı röportaj sonunda çete üyeliğinin fiziksel ve duygusal ihtiyaçları karşılayan bir koruyucu bir faktör olduğunu ortaya koymuştur.

Araştırmalar, erken müdahale programlarının çocuklarda yoksulluğun yarattığı olumsuz etkilere karşı fayda sağladığını göstermektedir. Bu müdahale programları hem ev ziyareti şeklinde gerçekleşen programlar hem de kurum bazlı programlar şeklinde olabilmektedir (Olds ve Kitzman, 1990).

Bu bağlamda, erken çocukluk döneminde yer alan çocukların ego sağlamlık düzeylerinin tespit edilmesi bu noktada çocuklara destek olunabilmesi açısından önemli görünmektedir. Ayrıca çocukların ego sağlamlık düzeylerinde fark oluşturan olguların tespit edilmesinin, risk altında bulunan çocukların tespitini kolaylaştıracağı ve desteğe gereksinim duyan çocuklara daha kolay erişim sağlanmasını mümkün kılacağı düşünülmektedir. Buradan hareketle bu araştırmanın amacı okul öncesi kuruma devam etmekte olan 50-72 aylık çocukların ego sağlamlık düzeylerinin çocukların yaşları, cinsiyetleri, anne-babalarının yaşları, anne-baba eğitim seviyesi, kardeş sayıları ve evde bakıcı bulunup bulunmaması değişkenlerine göre farklılaşıp farklılaşmadığının tespit edilmesidir.

\section{YÖNTEM}

\section{Araştırmanın Modeli}

Okul öncesi dönem çocukların ego sağlamlık düzeylerini çeşitli demografik özellikler açısından inceleyen bu araştırma betimsel tarama modelinde kurgulanmıştır. 


\section{Örneklem}

Veriler 2015-2016 eğitim-öğretim yılında, İstanbul İl Milli Eğitim Müdürlüğü’ne bağlı bağımsız ve resmi okul öncesi eğitim kurumlarına devam eden 50-72 aylık çocukların annelerinden toplanmıştır. Örneklem seçiminde öncelikle İstanbul merkez ilçeleri olarak kabul edilen Kadıköy, Beşiktaş, Maltepe, Sarıyer, Üsküdar, Şişli, Fatih ve Bakırköy’de yer alan resmi ve bağımsız anaokullarının isimleri numara ile kodlanmış, adı geçen semtlerde yer alan okullardan bir bağımsız iki resmi okul olacak şekilde basit rastgele örnekleme yöntemi kullanılarak okullar belirlenmiştir. Okullarda yer alan çocukların tümünün ailelerine ulaşılmaya çalışılmıştır. Ancak veliler gönüllülük esasına dayalı olarak çalışmaya katılmışlardır. Alana yaklaşık olarak 1200 ölçek dağıtılmış ancak 775 çocuğun velisinden gelen ölçekler değerlendirmeye alınmıştır. Araştırmaya katılan çocukların yaş ortalaması 65.03'tır. Araştırmaya katılan çocukların 397'si kız 378'i ise erkektir.

Tablo 1. Örneklemin yaşa ve cinsiyete göre dağılımı

\begin{tabular}{llcc}
\hline & & $\mathrm{f}$ & $\%$ \\
\hline \multirow{3}{*}{ Çocuk yaş grubu } & $50-57$ & 132 & 17.0 \\
& $58-64$ & 200 & 25.8 \\
& $65-72$ & 443 & 57.2 \\
& Toplam & 775 & 100.0 \\
\hline \multirow{3}{*}{ Cinsiyet } & Kiz & 397 & 51.2 \\
& Erkek & 378 & 48.8 \\
& Toplam & 775 & 100.0 \\
\hline
\end{tabular}

\section{Veri Toplama Araçları}

Araştırmada veri toplama aracı olarak; Kişisel Bilgi Formu ve Çocuk Ego Sağlamlığı Ölçeği (Anne Formu) kullanılmıştır.

Kişisel Bilgi Formu: Bu formda, çocuğun yaşı, cinsiyeti, devam ettiği okul türü gibi araştırmada ele alınan tüm demografik bilgilere dair sorular bu formda yer almaktadır.

Çocuk Ego Sağlamlı̆̆ı Ölçeği: Ölçek, çocukların anne-baba/veya öğretmen görüşleri doğrultusunda ego sağlamlıklarını ortaya koymayı amaçlamaktadır. Eisenberg ve arkadaşları tarafından 1996 yılında geliştirilmiştir. Türkçe’ye Önder ve Gülay-Ogelman (2011) tarafından uyarlanmıştır. 12 maddeden oluşan ölçek 9'lu likert tipi bir ölçektir. Ölçek tek boyuttan oluşmaktadır ve çocukların puanları arttıkça ego sağlamlık düzeylerinin arttı̆̆ı kabul edilmektedir. Türkçe'ye uyarlanan anne formunun içtutarlılık için ölçülen cronbach alfa değeri .86'dır (Önder ve Gülay-Ogelman, 2011). Yapılan bu çalışmada cronbach alfa değeri ,69 bulunmuştur. Bu güvenirlik seviyesinin yeterli düzeyde olduğu kabul edilebilir. 


\section{Veri Toplama Aşaması:}

Öncelikle ölçek sahiplerinden kullanım izni ve İstanbul İl Milli Eğitim Müdürlüğü’nden de okullarda veri toplamak için gerekli izinler alınmıştır. Ölçekler annelere açık zarf içinde gönderilmiş ve zarfların kapalı şekilde geri gönderilmesi istenmiştir. Zarflara araştırmanın amacını ve araştırmacıların iletişim bilgilerini içeren bilgilendirme notları eklenmiştir. $\mathrm{Bu}$ notlarda araştırmaya katılımın, gönüllülük esasına bağlı olduğu belirtilmiştir. Ölçeklerde annelere ve çocuklara ait kişisel bilgilere yer verilmemiştir, rumuz olarak numaralandırma yapılmıştır. Ölçekler öğretmenler aracılığıyla annelere dağıtılmış, annelerin çocuklarının ego sağlamlık düzeylerini değerlendirmeleri istenmiştir. Öğretmenler tarafından geri toplanan doldurulmuş ölçekler araştırmacılar tarafından okullardan teslim alınmıştır. Toplanan veriler içinde eksik işaretlenen ölçekler veriler arasından çıkartılmıştır. Elde kalan veriler araştırmacılar tarafından dijital veri tabanına aktarılmıştır.

\section{Verilerin Analizi:}

Analizler istatistiksel paket programı ile analiz edilmiştir. Verilerin analizinde ANOVA ve bağımsız grup t testi kullanılmıştır. Ayrıca, eğer yapılan analizler sonucunda Levene testi ile varyansların eşit olmadığı sonucuna ulaşıldığında robust testlerden olan ANOVA testinin alternatifi Welch testi uygulanmıştır.

\section{BULGULAR}

Araştırmada okul öncesi dönem 50-72 aylık çocukların ego sağlamlık düzeylerinin çocukların yaş gruplarına, cinsiyetlerine, anne yaşlarına, baba yaşlarına, annenin eğitim düzeyine, babanın eğitim düzeyine, kardeş sayılarına ve evde bakıcı olup olmaması durumuna göre farklılaşması incelenmiştir. Araştırmanın amacına yönelik soruların bulgularına bu bölümde yer verilmiştir. Aşağıdaki tabloda okul öncesi dönem çocuklarının yaş gruplarına göre ego sağlamlık düzeylerinin farklılaşıp farklılaşmadığı bulgusuna yer verilmiştir.

Tablo 2. Okul öncesi dönem çocuklarının ego sağlamlık düzeylerinin yaş gruplarına göre farklılaşıp farklılaşmamasına ilişkin ANOVA testi sonuçları

\begin{tabular}{lllllllll}
\hline Yaş grubu & $\mathrm{N}$ & $\mathrm{X}_{\text {ort }}$ & & $\begin{array}{l}\text { Kareler } \\
\text { toplamı }\end{array}$ & sd & $\begin{array}{l}\text { Kareler } \\
\text { ortalaması }\end{array}$ & $\mathrm{F}$ & $\mathrm{p}$ \\
\hline 50-57 ay & 130 & 5.50 & Gruplar içi & 1.173 & 2 & .586 & .445 & .641 \\
58-64 ay & 199 & 5.45 & Gruplar arası & 1009.549 & 766 & 1.318 & & \\
65-72 ay & 440 & 5.39 & & & & & & \\
\hline
\end{tabular}

Yukarıda yer alan Tablo 2 incelendiğinde, okul öncesi dönem çocuklarının ego sağlamlık düzeylerinde yaş gruplarının farklılaşmaya sebep olmadığı bulunmuştur $(F(2)=.445 ; p=.641)$. 
Aşağıda yer alan tabloda okul öncesi dönem çocuklarının ego sağlamlık düzeylerinin cinsiyetlerine göre farklılaşıp farklılaşmadığına ilişkin bulguya yer verilmiştir.

Tablo 3. Okul öncesi dönem çocuklarının ego sağlamlık düzeylerinin cinsiyetlerine göre farklılaşıp farklılaşmamasına ilişkin bağımsız grup testi sonuçları

\begin{tabular}{lllllll}
\hline Cinsiyet & $\mathrm{N}$ & $\mathrm{X}_{\text {ort }}$ & ss & sd & t & $\mathrm{p}$ \\
\hline Kiz & 39 & 5.51 & 1.12 & 756.647 & 2.076 & .038 \\
Erkek & 37 & 5.34 & 1.17 & & & \\
\hline
\end{tabular}

Tablo 3'de görüldüğü üzere, okul öncesi dönem çocuklarının ego sağlamlık düzeylerinin karşılaştırılması için yapılan bağımsız grup t testi sonucuna göre ego sağlamlık düzeylerinin birbirinden farklı olduğu bulunmuştur $(\mathrm{t}(756.647)=2.076 ; \mathrm{p}=.038)$. Buna göre ortalamalara bakıldığında kız çocukların erkek çocuklara göre ego sağlamlık düzeylerinin daha fazla olduğu bulunmuştur $\left(\mathrm{X}_{\mathrm{k} \text { zort }}=5.51 ; \mathrm{X}_{\mathrm{erkort}}=5.34\right)$.

Aşağıdaki Tablo 4' de okul öncesi dönem çocuklarının annelerinin yaşlarına göre ego sağlamlık düzeylerinin farklılaşıp farklılaşmadığı bulgusuna yer verilmiştir.

Tablo 4. Okul öncesi dönem çocuklarının ego sağlamlık düzeylerinin annelerinin yaşlarına göre farklılaşıp farklılaşmamasına ilişskin Welch testi sonuçları

\begin{tabular}{ccccccc}
\hline Anne yaş grubu & $\mathrm{N}$ & $\mathrm{X}_{\text {ort }}$ & $\mathrm{df1}$ & $\mathrm{df2}$ & Welch F değeri & $\mathrm{p}$ \\
\hline 30 ve alt1 & 168 & 5.35 & 2 & 413.750 & .478 & .620 \\
$31-40$ & 277 & 5.45 & & & & \\
41 ve üstü & 323 & 5.46 & & & & \\
\hline
\end{tabular}

Yukarıda yer alan Tablo 4 incelendiğinde, okul öncesi dönem çocuklarının ego sağlamlık düzeylerinde annelerinin yaşlarının farklılaşmaya sebep olmadığı ortaya çıkmıştır $\left(F_{\text {welch }}\right.$ $(2 ; 413.750)=.478 ; \mathrm{p}=.620)$.

Tablo 5'de okul öncesi dönem çocuklarının babalarının yaşlarına göre ego sağlamlık düzeylerinin farklılaşıp farklılaşmadığı bulgusuna yer verilmiştir.

Tablo 5. Okul öncesi dönem çocuklarının ego sağlamlık düzeylerinin babalarının yaşlarına göre farklılaşıp farklılaşmamasına ilişkin Welch testi sonuçları

\begin{tabular}{lllllll}
\hline Baba yaş grubu & $\mathrm{N}$ & $\mathrm{X}_{\text {ort }}$ & $\mathrm{df1}$ & $\mathrm{df2}$ & Welch F değeri & $\mathrm{p}$ \\
\hline 30 ve altı & 258 & 5.462 & 2 & 508.331 & 2.222 & .114 \\
$31-40$ & 247 & 5.305 & & & & \\
41 ve üstü & 264 & 5.508 & & & & \\
\hline
\end{tabular}

Yukarıda yer alan Tablo 5 incelendiğinde, okul öncesi dönem çocuklarının ego sağlamlık düzeylerinde babalarının yaşlarının farklılaşmaya sebep olmadığı bulunmuştur $\left(\mathrm{F}_{\text {welch }}(2 ; 508.331)=2.222 ; \mathrm{p}=.114\right)$. 
Tablo 6. Okul öncesi dönem çocuklarının ego sağlamlık düzeylerinin annelerinin eğitim düzeylerine göre farklılaşıp farklılaşmamasına iliş̧kin ANOVA testi sonuçları

\begin{tabular}{|c|c|c|c|c|c|c|c|c|}
\hline Anne eğitim düzeyi & $\mathrm{N}$ & $\mathrm{X}_{\text {ort }}$ & & $\begin{array}{l}\text { Kareler } \\
\text { toplamı }\end{array}$ & sd & $\begin{array}{l}\text { Kareler } \\
\text { ortalamas1 }\end{array}$ & $\mathrm{F}$ & $\mathrm{p}$ \\
\hline İlk-ortaokul & 170 & 5.33 & Gruplar içi & 4,026 & 2 & 2.013 & 1.538 & .175 \\
\hline Lise & 218 & 5.39 & Gruplar arası & 993.43 & 759 & 1.309 & & \\
\hline $\begin{array}{l}\text { Lisans- } \\
\text { lisans üstü }\end{array}$ & 374 & 5.50 & & & & & & \\
\hline
\end{tabular}

Yukarıda yer alan Tablo 6 incelendiğinde, okul öncesi dönem çocuklarının ego sağlamlık düzeylerinde anne eğitim düzeylerinin farklılaşmaya sebep olmadığı ortaya çıkmıştır (F $(2 ; 759)=1.538 ; \mathrm{p}=.175)$.

Aşağıdaki Tablo 7'de okul öncesi dönem çocuklarının babalarının eğitim düzeylerine göre ego sağlamlık düzeylerinin farklılaşıp farklılaşmadığı bulgusuna yer verilmiştir.

Tablo 7. Okul öncesi dönem çocuklarının ego sağlamlık düzeylerinin babalarının eğitim düzeylerine göre farklılaşıp farklılaşmamasına iliş̧kin Welch testi sonuçları

\begin{tabular}{lllllll}
\hline Baba eğitim düzeyi & $\mathrm{N}$ & $\mathrm{X}_{\text {ort }}$ & $\mathrm{df1}$ & $\mathrm{df2}$ & Welch F değeri & $\mathrm{p}$ \\
\hline İlk-ortaokul & 163 & 5.40 & 2 & 355.238 & 1.905 & .150 \\
Lise & 209 & 5.31 & & & & \\
Lisans ve lisans üstü & 394 & 5.50 & & & & \\
\hline
\end{tabular}

Yukarıda yer alan tablo 7 incelendiğinde, okul öncesi dönem çocuklarının ego sağlamlık düzeylerinde baba eğitim düzeylerinin farklılaşmaya sebep olmadığı tespit edilmiştir $\left(F_{\text {welch }}(2 ; 355.238)=1.905 ; \mathrm{p}=.150\right)$.

Aşağıdaki Tablo 8'de okul öncesi dönem çocuklarının kardeş sayılarına göre ego sağlamlık düzeylerinin farklılaşıp farklılaşmadığı bulgusuna yer verilmiştir.

Tablo 8. Okul öncesi dönem çocuklarının ego sağlamlık düzeylerinin kardeşs sayılarına göre farklılaşıı farklılaşmamasına ilişkin Welch testi sonuçları

\begin{tabular}{lllllll}
\hline Kardeş sayısı & $\mathrm{N}$ & $\mathrm{X}_{\text {ort }}$ & df1 & df2 & Welch F değeri & $\mathrm{p}$ \\
\hline 1 kardeş & 429 & 5.41 & 2 & 244.550 & 2.366 & .096 \\
2 kardeş & 244 & 5.53 & & & & \\
3 ve 3'ten fazla & 93 & 5.23 & & & & \\
\hline
\end{tabular}

Tablo 8 incelendiğinde, okul öncesi dönem çocuklarının ego sağlamlık düzeylerinde kardeş sayılarının farklılaşmaya sebep olmadığı görülmüştür $\left(F_{\text {welch }}(2 ; 244.550)=2.366 ; p=.096\right)$.

Okul öncesi dönem çocuklarının ego sağlamlık düzeylerinin evde bakıcının olup olmaması değişkenine göre farklılaşıp farklılaşmadığına ilişkin bulguya Tablo 9’ da yer verilmiştir. 
Tablo 9. Okul öncesi dönem çocuklarının ego sağlamlık düzeylerinin evde bakıcının olup olmaması değişkenine göre farklılaşıp farklılaşmamasına ilişkin bağımsız grup t testi sonuçları

\begin{tabular}{lllllll}
\hline Bakıc1 & $\mathrm{N}$ & $\mathrm{X}_{\text {ort }}$ & ss & sd & t & $\mathrm{p}$ \\
Var & 144 & 5.45 & 1.27 & 764 & 324 & .746 \\
Yok & 622 & 5.41 & 1.11 & & & \\
\hline
\end{tabular}

Tablo 9'da görüldüğü üzere, okul öncesi dönem çocuklarının ego sağlamlık düzeylerinin evde bakıcının olup olmaması değişkenine göre karşılaştırılması için yapılan bağımsız grup t testi sonucuna göre ego sağlamlık düzeylerinin birbirinden farklı olmadığı bulunmuştur $(\mathrm{t}(764)=324 ; \mathrm{p}=.746)$.

\section{SONUÇ ve TARTIŞMA}

Araştırma sonuçlarına göre çocukların ego sağlamlık düzeylerinde çocukların cinsiyetlerine göre anlamlı bir farklılık tespit edilmiştir. Ego sağlamlık düzeyleri cinsiyet açısından değerlendirildiğinde kızlar lehine anlamlı bir farklılık olduğu elde edilmiştir. Ancak çocuğun yaş grubu, anne-babanın yaşı, anne-babanın eğitim düzeyi, kardeş sayısı, evde bakıcı olup olmaması durumuna ilişkin değişkenlerin çocukların ego sağlamlık düzeylerinde farklılık yaratmadığı görülmüştür. Aşağıda öncelikle bulgularda izlenen sıraya bağlı kalarak ego sağlamlığı üzerinde etkisi olan ve olmayan değişkenler kendi içinde tartışıldıktan sonra bulgulara yönelik öneriler üzerinde durulmuştur.

Ego sağlamlığına etki eden değişkenleri tespit etmek amacıyla yapılan bu araştırmada yaş grupları açısından değerlendirmede bir farklılık bulunmamıştır. Luthar (1999) yaptığı araştırmada cinsiyet farkı gözetmeksizin küçük yaştaki çocukların ergen ve gençlere oranla tüm risk faktörlerine karşı birçok yönden daha savunmasız olduklarına ilişkin bir görüş bildirmiştir. Son yıllarda küçük çocuklarla yapılan araştırmalar ise, okul öncesi dönem çocuklarda ego sağlamlığının yaşla farklılaşmadığını ortaya koymuştur. Örneğin, Taylor ve diğerlerinin (2013) yaptığı boylamsal araştırmada 18., 30. ve 42. aylarda çocukların ego sağlamlık düzeylerinin sabit kaldığı saptanmıştır. Benzer şekilde Türkiye'de yapılan bir araştırma, 60-72 aylık çocukların ego sağlamlık düzeylerinin yaşa bağlı olarak farklılaşmadığını ortaya koymaktadır (Önder, Balaban-Dağal ve Bayındır, 2016). Bu araştırmanın sonuçları da güncel araştırma sonuçlarına benzer şekilde okul öncesi dönemde aylık yaş grupları arasında anlamlı farklıkların olmadığg görüşünü desteklemektedir.

Ego sağlamlığı üzerinde cinsiyet değişkenin yarattığı etkiye bakıldığında kızlar lehine anlamlı bir farklılık tespit edilmiştir. Ego sağlamlığı ve cinsiyet arasındaki ilişkiyi inceleyen öncü araştırmalar yetişkinlikten önce erkeklerin, yetişkinlikten sonra kızların daha fazla risk taşıdığını belirtmektedir (Gamble ve Zigler, 1986; Rutter, 1989). Eğer bu durum yetişkinlik 
öncesi erkeklerin ego sağlamlık düzeyinin kızlardan daha düşük olduğu şeklinde yorumlanacak olursa bu araştırmanın sonuçları ile benzerlik gösterdiği şeklinde düşünülebilir. Ancak küçük çocuklarla hem yurt dışında hem de yurt içinde yapılan araştırmalar, çocukların cinsiyeti ve ego sağlamlık düzeyleri arasında ilişki olmadığını göstermektedir (Önder vd., 2016; Taylor vd., 2013). Oktan, Odacı ve Berber-Çelik'in (2014) üniversite öğrencileriyle yapmış olduğu araştırmada, kız öğrencilerin psikolojik sağlamlık puan ortalamalarının erkeklere göre daha yüksek olduğu bulunmuştur. Yüksek risk altındaki çocuklarla yapılan doğumdan 32 yaşına kadar bireylerin takip edildiği boylamsal bir çalışmada ise cinsiyet, ego sağlamlığı ile ilgili bir faktör olarak belirtilmiştir (Werner,1989).

Anne-babanın yaşı da çocukların ego sağlamlık düzeylerinde bir farklılığa sebep olmamıştır. Bu konuda herhangi bir kaynağa erişilememekle birlikte, bu araştırma sonucundan hareketle ebeveyn yaşının ego sağlamlığının önemli bir yordayıcısı olmadığı söylenebilir. Benzer şekilde, anne-babanın eğitim seviyesinin, ego sağlamlık düzeylerine etkisi incelendiğinde bir farklılık tespit edilememiştir. Ancak, ailenin eğitim seviyesinin çocukların ego sağlamlık düzeylerinde farklılık yarattığını gösteren araştırmalar bulunmaktadır (Gianesini, 2011; Sangma, 2014; SueLynn ve Yoo'nun, 2015). Sue-Lynn ve Yoo'nun (2015) ergenlerle yapmış oldukları bir araştırmada anne-babanın eğitim seviyesinin ego sağlamlık düzeylerine, eğitim seviyesi yüksek anne-babalar lehine etki ettiği saptanmıştır. Benzer şekilde Sangma'nın (2014) büyük çocuklarla yapmış olduğu araştırmada da, babalarının eğitim düzeyi 12 yıldan fazla olan çocukların ego sağlamlıklarının yüksek olduğu ortaya çıkmıştır. Ancak aynı araştırma, annenin mesleki uğraşının yüksek olmasının çocuklarının ego sağlamlığını düşürdüğünü de ayrıca ortaya koymaktadır.

Çocukların ego sağlamlık düzeyleri ile kardeş sayıları arasında da anlamlı bir farklılık bulunamamıştır. Nitekim Sangma (2014) 8-12 yaş grubu çocuklarla yapmış olduğu araştırmada da, ailenin büyüklüğü (ailede birey sayısının fazla olması) ile sağlamlık arasında bir farklılığın olmadığını bulmuştur. Ancak Gianesin'nin (2011) 16-30 yaş arasındaki bireylerle yapmış olduğu araştırmada, ailedeki birey sayıları ile ego sağlamlık düzeyleri arasında pozitif bir ilişki olduğu ortaya koyulmuştur.

Çocukların maruz kaldığı çeşitli risk faktörleri, madde bağımlılığı, şiddet içeren davranış, düşük akademik başarı ve okul terki, genç gebelik, ruhsal sağlık bozuklukları ve duygusal s1kıntılar gibi problemlere neden olabilmektedir (Brooks, 2006; Fergus ve Zimmerman, 2005; Resnick, 2000). Bu nedenle risk faktörlerini azaltmak bir müdahale olabileceği gibi öncelikli olarak risk faktörlerine maruz kalan bireylerin güçlendirilmesine başvurulmalıdır. 
Müdahalelerin risk iyileştirmesine odaklanmak yerine, riske maruz olanlar için kaynak geliştirme üzerine yoğunlaşması gerektiğini belirten görüşler vardır (Fergus ve Zimmerman, 2005). Bu görüş kabul edildiğinde yapılabilecek müdahalelerin biri, risk faktörlerine maruz kalan bireylerin bu risk faktörlerine karşı dirençli hale gelmesine bireysel boyutta yardımcı olacak destek programların uygulanmasıdır. Ego sağlamlıklarının geliştirilmesini hedefleyen bu tür programların özellikle erken çocukluk döneminde uygulanmasının önemi açıktır. Ancak bireysel boyutta desteğin yanı sira yapılabilecek düzenlemeler de vardır. Benzies ve Mychasiuk'e göre (2009), psikolojik sağlamlığın en üst düzeye çıkarılması için sosyo-ekolojik modelin birey, aile ve toplum olmak üzere tüm etkileşimli seviyelerindeki koruyucu faktörlerin güçlendirilmesi hedeflenmelidir.

Araştırmada kullanılan rastgele seçim örnekleme yöntemi araştırma sonuçlarının genellenebilir özelliğini arttırmaktadır. Ancak araştırma ile ilgili belirtilmesi gereken bazı sınırlılıklar vardır. Araştırmanın en önemli sınırlılı̆̆ı hem demografik verilerin hem de çocukların ego sağlamlığına dair verilerin annelerden alınan bilgiler doğrultusunda değerlendirilmiş olmasıdır. Verilerin farklı örneklem gruplarından toplanması, farklı sosyoekonomik düzeylere ulaşarak çalışmanın yinelenmesi, ego sağlamlığı açısından risk altında olan çocukların ortaya çıkartılması ve onlara ilişkin önlem alma çalışmalarının yapılabilmesi açısından önemli olacaktır. Ayrıca sonraki araştırmalarda ilgili literatür ışığında erken çocukluk dönemindeki çocukların ego sağlamlık düzeylerini etkileme olasılığı bulunan ebeveynlik tutumları, sosyal destek unsurları gibi farklı değişkenlerin de incelenmesi önerilebilir.

\section{KAYNAKÇA}

Alvord, M. K. ve Grados, J. J. (2005). Enhancing resilience in children: A proactive approach. Professional Psychology: Research and Practice, 36(3), 238-245, http://dx.doi.org/10. 1037/0735-7028.36.3.238.

Baydar, N. ve Akçınar, B. (2015). Ramifications of socioeconomic differences for three year old children and their families in Turkey, Early Childhood Research Quarterly, 33, 3348. http://dx.doi.org/10.1016/j.ecresq.2015.05.002.

Bayındır, D., Önder, A. ve Balaban Dağal, A. (2016). Temperament and Resiliency as Predictor Factors of Preschoolers' School Readiness (Öz). 10. Sosyal ve Davranış Bilimleri Araştırma Konferansında sunulan bildiri, Saraybosna Üniversitesi, Saraybosna.

Benzies, K. ve Mychasiuk, R. (2009). Fostering family resiliency: A review of the key protective factors. Child \& Family Social Work, 14, 103-114.

http://dx.doi.org/10.1111/j.1365-2206.2008.00568x. 
Block, J. ve Block, J. H. (2006). Venturing a 30-year longitudinal study. American Psychologist, 61, 315-327. doi:10.1037/0003-066X.61.4.315.

Bradley, R. H., Whiteside, L. Munford, D. J., Casey, P. H., Kelleher, K. J. ve Pope, S. K. (1994). Early indications of resilience and their relation to experiences in the home environments of low birthweight, premature children living in poverty. Child Development, 65(2), 346360 .

Brooks, J. E. (2006). Strengthening resilience in children and youths: Maximizingopportunities in the schools. Children and Schools, 28(2), 69-76.

Brown, J., Barbarin, O. ve Scott, K. (2013). Socioemotional Trajectories in Black Boys Between Kindergarten and the Fifth Grade: The Role of Cognitive Skills and Family in Promoting Resiliency. American Journal of Orthopsychiatry 83, (2,3) 176-184. doi: 10.1111/ajop.12027.

Criss, M. M., Pettit, G. S., Bates, J. E., Dodge, K. A. ve Lapp, A. L. (2002). Family adversity, positive peer relationship, and children's externalizing behavior: A longitudinal perspective on risk and resilience. Child Development, 73, 1220-1237.

Compas, B. E., Jaser, S. S. ve Benson, M. A. (2009). Coping and emotion regulation: Implications for understanding depression during adolescence. İçinde S. NolenHoeksema \& L. M. Hilt (Edi.), Handbook of depression in adolescents (s. 419-440). New York, NY: Routledge/Taylor \& Francis Group.

Coyne, L. W. ve Thompson, A. D. (2011). Maternal depression, locus of control, and emotion regulatory strategy as predictors of preschoolers' internalizing problems. Journal of Child and Family Studies, 20, 873-883. doi:10.1007/s10826-011-9455-2.

Çelik, E. (2013). Lise Son Sınıf Öğrencilerinin Yılmazlık Özelliklerinin Duygusal Dışavurum Açısından İncelenmesi. Atatürk Üniversitesi Sosyal Bilimler Enstitüsü Dergisi, 17 (2), 221-236.

Derryberry, D. ve Reed, M. A. (1996). Regulatory processes and the development of cognitive representations. Development and Psychopathology,8,215-234.

Eisenberg, N., Fabes, R. A., Guthrie, I. K., Murphy, B. C., Maszk, P., Holmgren, R. ve Suh, K. (1996). The Relations of Regulation and Emotionality To Problem Behavior in Elementary School Children. Development and Psychopathology, 8: 141-162.

Eisenberg, N., Spinrad, T.L., Fabes, R.A., Reiser, M., Cumberland, A., Shepard, S.A. ve diğerleri (2004). The relations of effortful control and impulsivity to children's resiliency and adjustment. Child Development, 75 (1), 25 - 46.

Fergus, S. ve Zimmerman, M. A. (2005). Adolescent resilience: A framework for understanding healthy development in the face of risk. Annual Review of Public Health, 26,399-419, doi: 10.1146/annurev.publhealth.26.021304.144357

Gamble, T. J. ve Zigler, E. (1986). Effects of infant day care: Another look at the evidence. American Journal of Orthopsychiatry, 56, 26-42. 
Gianesini, G. (2011). Resilience As a Relational Construct: Theoretical and Empirical Evidences. $\quad 6 \quad$ Şubat $2018 \quad$ tarihinde http://paduaresearch.cab.unipd.it/4432/2/PH_thesis_2012_(in_stampa_24-012012).pdf adresinden erişildi.

Gilligan, R. (2000). Adversity, resilience and young people: The protective value of positive school and spare time experiences. Child and Society, 14(1), 37-47.

Gizir, C. A. (2007). Psikolojik sağlamlık, risk faktörleri ve koruyucu faktörler üzerinde bir derleme çalışması. Türk Psikolojik Danışma ve Rehberlik Dergisi, 3, 28, 113-128.

Keenan, K. ve Shaw, D. (1997). Developmental and social influences on young girls' early problem behavior. Psychological Bulletin, 121, 95-113. doi:10.1037/00332909.121.1.95.

Kwok, O., Hughes, J. N. ve Luo, W. (2007). Role of resilient personality on lower achieving first grade students' current and future achievement,Journal of School Psychology, 45, 61-82.

Lengua, L.J., Sandler, I.N., West, S.G., Wolchik, S.A. ve Curran, P.J. (1999). Emotionality and self-regulation, threat appraisal, and coping in children of divorce. Development and Psychopathology, 11(1):15-37.

Luthar, S. S. (1991). Vulnerability and resilience: A study of high-risk adolescents. ChildDevelopment, 62, 600-616.

Luthar, S. (1999). Poverty and children's adjustment. New-bury Park, CA: Sage.

Masten, A. ve Coatsworth, J. D. (1998). The development of competence in favorable and unfavorable environments: Lessons from research on successful children. American Psychologist, 53(2), 205-220.

Masten, A. S. (2011). Resilience in children threatened by extreme adversity: Frameworkfor research, practice, and translational synergy. Development and Psychopathology,23, 493-506. doi: 10.1017/S0954579411000198

Mathiesen, K. S., Sanson, A., Stoolmiller, M. ve Karevold, E. (2009). The nature and predictors of undercontrolled and internalizing problem trajectories across early childhood. Journal of Abnormal Child Psychology, 37, 209-222. doi:10.1007/s10802-008-9268-y.

McCubbin, M., Balling, K., Possin, P., Frierdich, S. ve Bryne, B. (2002). Family resiliency in childhood cancer. Family Relations, 51, 103-111. 
McLoyd, V. C. (1998). Socioeconomic disadvantage and child development. American Psychologist, 53(2), 185-204.

McLoyd, V. C. ve Wilson, L. (1990). Maternal behavior, social support, and economic conditions as predictors of distress in children. New Directions for Child Development, 46, 49-69. doi:10.1002/cd. 23219904605.

Oktan, V., Odacı, H., ve Berber Çelik, Ç. (2014). Psikolojik doğum sırasının psikolojik sağlamlığın yordanmasındaki rolünün incelenmesi. Abant İzzet Baysal Üniversitesi Eğitim Fakültesi Dergisi, 14 (1), 140-152.

Olds, D.L. ve Kitzman, H. (1990). Can home visitation improve the health of woman and children at enviromental risk? Pediatrics, 86, 108-116.

Önder, A., Balaban Dağal, A. ve Bayındır, D. (2016,Aralık). The Effect of Emotion Regulation Skills on Ego Resilience in Preschoolers (Öz).8th International Conference on Learning, Education and Pedagogy (LEAP), Dubai. Erişim adresi: https://adtelweb.org/proceeedings/17.pdf

Önder, A. ve Gülay-Ogelman, H. (2011). The Reliability-Validity Study fort he Ego Resiliency Scale (Teacher-Mother-Father Forms) for Children Aged between 5 and 6, Uluslararasi Hakemli Akademik Sosyal Bilimler Dergisi, 2(1), 5-21.

Prince-Embury, S. (2015). Assessing personal resiliency in school settings: The resiliency scales for children and adolescents. Journal of Psychologists and Counsellors in Schools, 25 (1). 55-65.

Power, T.G. (2004). Stress and coping in childhood: The parents' role. Parenting: Science and Practice, 4, 271-317. doi:10.1207/s15327922par0404_1

Rak, C. F. ve Patterson, L. E. (1996). Promoting resilience in at-risk children. Journal of Counseling and Development, 74, 368-373.

Resnick, M. D. (2000). Protective factors, resiliency, and healthy development. AdolescentMedicine: State of the Art Reviews, 11(1), 157-164.

Rothbart, M. K., Ahadi, S. A. ve Evans, D. E. (2000). Temperament and personality: Origins and outcomes. Journal of Personality and Social Psychology, 78(1), 122-135. doi: 10.1037//0022-3514.78.1.121.

Rutter, M. (1989). Pathways from childhood to adult life. Journal of Child Psychology and Psychiatry, 30, 25-51.

Rydell, A. M., Berlin, L. ve Bohlin, G. (2003). Emotionality, emotion regulation, and adaptation among 5- to 8-year-old children. Emotions, 3(1), 30-47.

Sangma, K. (2014). The effects of ego-resilience on the trajectories of school adaptation among adolescents in poverty, Yayınlanmamış Yüksek Lisans Tezi. Dharward Üniversitesi, İnsan Bilimleri: İnsan Gelişimi ve Aile Çalışmaları Bölümü. 
Smokowski, P. R., Reynolds, A. J. ve Bezruczko, N. (1999). Resilience and protective factors in adolescence: An autobiographical perspective from disadvantaged youth. Journal of School Psychology, 37,4, 425-448.

Stipek, D., Recchia, S. ve McClintic, S. (1992). Self evaluation in young children. Monographs of the Society for Research in Child Development, 57 (1, Serial No. 226).

Sue- Lynn, K. ve Yoo, J.P. (2015). The Effects of Ego-Resilience on the Trajectories of School Adaptation among Adolescents in Poverty (Öz). Bangkok Uluslararası Sosyal Bilimler Konferansinda sunulan bildiri, Bangkok, Tayland.

Taylor, Z.E., Eisenberg, N., Spinrad, T.L. ve Widaman, K.F. (2013). Longitudinal relations of intrusive parenting and effortful control to ego-resiliency during early childhood, Child Development, 84 (4), 1145-1151.

Ungar, M., Brown, M., Liebenberg, L., Othman, R., Kwong, W.M., Armstrong, M. ve Gilgun, J. (2007). Unique pathways to resilience across cultures. Adolescence, 42 (166), 287-310.

Werner, E. E. (1989). High risk children in young adulthood: A long itudinal study from birth to 32 Years. American Journal of Orthopsychiatry,59(1),72-81.

Wolkow, K. E. ve Ferguson, H. B. (2001). Community factors in the development of resiliency: Considerations and future directions. CommunityMental Health Journal, 37(6), 489-498.

Wyman, P. A., Cowen, E. L., Work, W. C. ve Parker, G. R. (1991). Developmental and family milieu interview correlates of resilience in urban children who have experienced major life-stress. American Journal ofCommunity Psychology, 19, 405-426.

Zolkoski, S.M. ve Bullock, L.M. (2012). Resilience in children and youth: A review. Children and Youth Services Review, 34, 2295-2303. 